\title{
New Literacy in Saudi Arabia
}

\section{Ibrahim Alfarhan}

\author{
Graduate Student, School of Education,
}

Saint Louis University, St. Louis, United States of America

ibrahim_uni@hotmail.com

Abstract: The mandated curriculum of Saudi Arabian schools is archaic; designed for generations long past. The era of only teaching young women to be homemakers and wives while young men are restricted to learning how to be homeowners, husband, and suitable neighbors must come to an end. The tragic reality is that the mandated national curriculum does not address the contemporary world, and the requirements of Saudi students to meet that world. The purpose of this paper is to address the issues of new literacy in Saudi Arabia and how curriculum should be reformed to deal with this situation. "New literacy comes with new social practice, new visual literacies, new video literacies, and other new literacies that are important to create new knowledge and improve individual life." (Leu, McVerry, Zawilinski, \& O’Byrne, 2007).

Keywords: New Literacy, Literacy and Education, School and Society, Curriculum, Learning Spaces, Classroom Management, Saudi Arabian Education.

\section{INTRODUCTION}

Lamya was seventeen when she stopped going to high school in Saudi Arabia. She is very smart, and according to her teachers was the best student in her class. When asked why, despite doing such excellent work she left school, she responded "I did not find myself interested, and challenged by the subjects I had to take. Everything I was reading only encouraged me to become a homemaker, but that's not what I want. I wanted to help increase my family's income by working with an online marketing firm. I would not have achieved my dream if I had continued at a traditional school."

On the first day of high school, Omar wanted to bring his iPod2 because he felt it included everything he enjoys and needs both for personal and school needs. When he attempted to enter school with it, he was stopped by the school administrator who stated that neither the school nor national policy allowed private technology on campus. This was a cruel surprise for Omar, who felt he would need it when he reached high school.

"I'm living in an industrial area. There are a lot of companies here dealing with new technology, why should I have to study how to feed camels?!" Omar thought. Though discouraged, he set his mind to learn what he needed to to reach his goals in life.

Lamya and Omar, the youth of today, represent the mindsets of a vast majority of adolescents in Saudi Arabia; who have a different lifestyle from past generations. Theirs is a new generation, one that's knowledgeable, and more importantly, confident in abilities to survive in the techno-world of today.

Unfortunately, the mandated curriculum of Saudi Arabian schools is archaic; designed for generations long past. The era of only teaching young women to be homemakers and wives while young men are restricted to learning how to be homeowners, husband, and suitable neighbors must come to an end. The tragic reality is that the mandated national curriculum does not address the contemporary world, and the requirements of Saudi students to meet that world. 
The Saudi Arabian curriculum is entirely different from that of the United States where the curriculum is structured on a theory plus fact baseline which promotes individual thought and expression giving the students the tools necessary for today's world. In Saudi Arabia, it is regulated exclusively by government requirements, and not by those of society. It is important that Saudi schools change their rationale to realistically align with the demands of the country's economy, commerce, technology, and society.

The current generation of young Saudi's will not benefit from an archaic educational curriculum that does not prepare them to become viable members of today's technologically dominated world. New knowledge, skills and theories can, and must be used as a roadmap to help this generation, attain a firm position in the macrocosm of Saudi and world constructs.

\section{DEFINING NEW LITERACY}

For a long time, literacy was deeply rooted in how to read or write, and the necessary skill sets. However, the new literacy of today is entirely different. "The literacy of today is associated with people's daily lives. Moreover, people recognize new literacy as a part of their social practice." (Pahl \& Rowsell, 2005). In fact, the Internet is one influence that is shaping new literacy. "It is clear that the Internet is this generation defining [sic] technology for literacy and learning. It is also clear that classrooms have yet to take up Internet integration systematically, let alone instruction in the new literacies the Internet requires. In fact, those pioneering teachers who have led the way with Internet integration focus on the technology aspects of use, not seeing this as an instructional issue for literacy at all." (Karchmer, 2001). The Internet is this generation's defining technology for literacy and learning. (Leu, McVerry, Zawilinski, \& O’Byrne, 2007). Likewise, "new literacy comes with new social practice, new visual literacies, new video literacies, and other new literacies that are important to create new knowledge and improve individual life." (Leu, McVerry, Zawilinski, \& O’Byrne, 2007).

Despite the fact that most students are familiar with modern technology, Saudi Arabian schools do not follow the new literacy. There is a definite need for change, but to some roadblocks must be overcome before that can be accomplished. Old mindsets must change and new goals must be established, however, to do that, the focus must be on the future.

The first step in obtaining new goals is to address the needs of the educators to align the curriculum with new literacy and concentrate it on the interests and goals of the students. Too often, when school systems measure their success, they tend to look at the students in terms of grade point averages and graduations $v$ failures. In the new literacy, students are required to be actively involved in the learning process, and shaping the classrooms for improved learning atmospheres. "This is especially true today where the Internet is used by more than 1.4 billion individuals: they use it to read, write and communicate online." (Leu, McVerry, Zawilinski, \& O'Byrne, 2007). Therefore, to familiarize instructional staff in new literacy, schools must work harder to improve the students' learning environments (space), explore their identities, relate education to social/economic situations and make their texts more inclusive.

Students must be taught to practice their new knowledge and skills in their own homes and communities as well as in school as each brings experience and knowledge with them. Therefore, schools must assist students to connect the external world classroom with the internal school classroom to correlate and apply learned knowledge from both. This is called "Third Space Theory."

"The "Third Space Theory" encourages students to write about their home experience outside of their homes. Another application of the theory has been used to describe the in-between literacy practice of prisoners." (Pahl \& Rowsell, 2005). 
The "Third Space Theory" must be applied to Saudi Arabian schools them to adapt to students' experiences instead of isolating them from their homes, communities and the world. This is not a complicated process can only benefit in allowing students to share experiences in their third space. For example, when teachers ask students to bring their favorite books to class, an active link develops between school and home in the third space, and students have an opportunity to learn what they enjoy, as well as what they need to attain their goals.

Exploring students' identities is another important issue in schools that needs to be addressed. Schools serve a vital function in bringing together students with divergent interests, knowledge and life experience. When allowed to share, the knowledge each student possesses may be new insights other students might need to excel. Identities shaped by a variety of socio-economic factors are vital preparing students to face the challenges of a more open and progressive world.

"Indeed, students come with much rich knowledge as well as different levels of understanding language. Therefore, educators need to take account of students' identities in a different space." (Pahl \& Rowsell, 2005). It is illogical to teach literacy without caring for students' identities. Thus, teachers have to work hard in order to explore those identities. By exploring and learning from them, teachers can structure the curriculum and classroom to better meet the students' identities. "There are many ways within the classrooms to facilitate a connection between identity and class materials, and if both of these are considered, students' identities may be investigated and opened up in practice." (Pahl \& Rowsell, 2005). However, the educational system in Saudi Arabia does not address the issue of student identity.

An additional area of concern relates students' education in their social practices. Schools must make a connection between themselves and the students' home environments through social practice. "There is a fallacy in the belief that a man is born free, for a man is born in his culture and society where he shapes his characteristics." (Counts, 1978). Therefore, schools need to understand what students encounter in their lives to better help them to identify and practice positive attributes in schools, and in their lives.

However, Saudi Arabian schools have not sought to encourage students to practice their real lives in the classroom. Dewey summarizes this problem, which applies to Saudi Arabia, by saying, "What, then, is the problem? It is just to get rid of the prejudicial notion that there is some gap in kind (as distinct from degree) between the child's experience and the various forms of subject-matter that make up the course of study" (Dewey, 2007, p. 11). "Therefore, schools should take the concept of literacy as social practice to help students to see literacy as connected to other things." (Pahl \& Rowsell, 2005). For example, when students are asked to practice completing a bank application or book airline tickets online, schools are bringing students' social needs into classrooms. Schools identify areas that are lacking in their lives and bring those to the classrooms to better encourage students to improve, and overcome their problems.

\section{IMPROVING LITERACY}

Yet another method schools must apply to improve student performance is making their texts more inclusive. In Saudi Arabia, textbooks are written by the government without student contribution, an invaluable overlooked asset for a progressive system. These texts include only prescribed information and print media. As the schools of today must adjust to a new literacy, it is not only written but also updated audio-visual materials that must be included in the curriculum. Indeed, songs now forbidden for Saudi students to listen to are one type of new literacy that must be accessible. This will encourage them to think and learn to make intelligent decisions. Therefore, if Saudi Arabians want to transfer to new literacy, it must be an all-inclusive improvement incorporating these and other materials that students are exposed to daily through the Internet and other outside sources.

\section{Volume 2}


Both ideas, social responsibility, and relevance, come together when Selfe and Hawisher assert in Literate Lives in the Information Age that. "...if literacy educators continue to define literacy only in terms of alphabetic practice only, in ways that ignore, exclude, or devalue new media texts, they not only abdicate professional responsibility to describe the ways in which humans are now communicating and making meaning, but they also run the risk of their curriculum no longer holding relevance for students who are communicating in increasingly expansive networked environments." (Selfe \& Hawisher, 2004, p. 233)

For Selfe and Hawisher, it's about giving all students the opportunity to participate in the new literacy that exists in our world as well as continuing our relevancy as a field. Digital spaces are fast becoming part of our composition curricula.

Thus, from this point forward, Saudi Arabian schools must construct and promote contemporary curricula with published texts that include audio-visual media and other adjunct new literacy materials. In this way, schools will be encouraging students to enjoy studying and the new literacy opportunities in their classrooms.

The second aspect of improving literacy revolves around the classrooms themselves. Classrooms are the focal point of learning for students - be they lecture halls, conventional classrooms, labs or outside scenarios, formal education begins in the classroom where throughout their studies students will spend the majority of their time. To accomplish this, each class and instructor must be prepared and proficient with assisting students in attaining their educational goals through new knowledge and experiences.

Currently in Saudi Arabia, students are expected to stay in their seats for the entire seven hour school day without any form of recreational break. Is it any wonder students hate the term "class?" However, in the new literacy, the situation is entirely different. The classroom will be a place where-where students can play, sing, read, and talk and enjoy learning. This will aid them in applying prescribed knowledge combined, through healthy camaraderie with the experience shared by their peers in and out of school.

The teacher's role will be one of guiding instruction while creating a positive physical and mental atmosphere for learning. It is this cooperative participation in the educational system that will be equally valuable in the creation of a new Saudi Arabia.

The initial issue of the classroom is how the new literacy will be taught. In the old literacy, students listened to their teachers, then answered questions. According to Dewey, (2007) in the traditional way, "There is very little place in the traditional schoolrooms for the child to work. The workshop, the laboratory, the materials, the tools with which the child may construct, create, and actively inquire, and even the requisite space, have been for the most part of lacking" (Dewey, 2007, p. 32). However, in new literacy, students are challenged differently; they are asked to involve problem solving, evaluation, and application by using visual and other media. In partnership with that, they have the opportunity to improve their critical literacy skills to criticize and argue with a range of texts. The application of the new literacy in classrooms "... encourages students to engage in intercultural communication to negotiate and solve problems across cultures and languages." (Pahl \& Rowsell, 2005).

The second issue is how students are practicing new literacy outside the classroom. What happens when today's Saudi Arabian students leave their classrooms? The norm appears to be the student forgets what they learned in class because there is no literacy connection to the world outside the classroom.

Alvermann and McLean (2007) describe how to make this association between schools and classrooms. "Much can be learned that has potential implications for classroom teachers from attending carefully to how adolescents who struggle to read, for what reason (motivational, linguistic, cognitive, social, or any combination of such), use certain practices to shape their own identities as literate beings when they are using new literacies 
in informal, out-of-school Learning." (Alvermann \& McLean, 2007, p. 8) Therefore, educators must be required to help students continue to relate what they learn in the class to other environs. As an example is students in the first grade must learn to connect each alphabetic sound to its symbol. However, with the addition of asking students to access Internet websites such as 4KIDS or Quizlet, each of which offers educational games that reinforce what they learned in class by applying it outside of school. This method helps bridge the gap between schools and the community both of which are vital parts of their lives.

The third class issue is student must be able to participate in the planning and implementation of the new literacy. A valuable asset is wasted by the Saudi system that makes teachers solely responsible for class plans - there is no student participation.

"For a long time in teaching literacy, it has been noted that students will not learn how to read or write well if they spend the whole class time in a single class group." (Fisher, Rothenberg, \& Frey, 2007). Fisher and others suggest that from now from on, students and teachers should work together to create a plan for the class (Fisher, Rothenberg, \& Frey, 2007).

Good teachers are cognizant of the variable learning weaknesses of students, thus having the ability to construct their classes to accommodate weaknesses gives students the opportunity to challenge, and potentially overcome them. However, this is not easy to apply in Saudi Arabia's classrooms where the size of the classroom is often 40 students. To engage students and challenge their weaknesses, it is important to resize the classroom to a maximum 15 students. In this manner, the teacher would have more opportunity to address the challenges of each student and work to accommodate and/or eliminate them.

The fourth issue concerns how well students understand and apply the knowledge they learn in class. The ultimate goal must be a student who has been taught to identify, analyze and address positive and negative issues they face throughout life. A student who graduates with the knowledge he can apply to his life, the life of his loved ones, his community, and his country is a benefit to all. They are the ones whose lives are not short stories, they're novels.

"In addition, after using a text, teachers have to encourage their students to act and think critically, and appreciate and understand the instruction. That allows them to improve their problem solving skills." (Pahl \& Rowsell, 2005).

Example, a Geography assignment might include mapping out driving directions for a Martian one has invited to dinner. The student will be required to apply critical thinking, learned skills and theories to generate precise travel directions from Mars to his/her front door noting each action to be taken to complete. Enhancement might include the inclusion of geopolitical boundaries and complications which might be encountered that may prove hazardous. Additional options may, at the discretion of the student be added to demonstrate his/her critical thinking abilities.

\section{CONCLUSION}

Only by changing attitudes and focusing on students and classrooms, can Saudi Arabia convert the traditional literacy curriculum to the new literacy. Then, and only then will students have a more active place in their classrooms. We Saudis have all the elements necessary to achieve that. The only thing remaining is for our government to give the educators a democratic environment and trust them; if done, education will develop a generation of students who will realize the benefits of sound education and in turn be of benefit to the entire country and ultimately the world. 


\section{REFERENCE}

Blog,\& Theme,T. S. (2014). Agile learning spaces.

Retrieved from https://bluyonder.wordpress.com/tag/agile-learning-spaces/

Counts, G. S. S. (1978). Dare the school build a new social order?. United States: Southern Illinois University Press.

Dail, J. S., \& Giles, T. (2011). The hunger games and little brother come to life on VoiceThread: Helping students respond visually to young adult literature. Alan Review, The, Volume 39, Number 3(Summer, 2012), 0-1. doi:n.

Dewey, J. (2008). The child and the curriculum ; including, the school and society. New York: Cosimo Classics.

Dewey, J. (2008). The child and the curriculum including, the school and society. United States: Cosimo Classics.

Fisher, D. (2008). Language learners in the English classroom. United States: National Council of Teachers of English.

Fisher, D., Rothenberg, C., \& Frey, N. (2008). Language learners in the English classroom. United States: National Council of Teachers of English.

Hansen, D. t. (1999). Understanding Students. ProQuest.com, 14(2), 171-85. Retrieved from http://search. proquest.com/openview/e36f7c9d12d6bd48991b8c9762735e4f/1?pq-origsite=gscholar

Karchmer, R. (1996). International literacy association. Reading Research Quarterly, 36(4), 442-466. doi:10.1598/RRQ.36.4.5

Karchmer, G. (2009). What Is New about the New Literacies of Online Reading Comprehension? Retrieved from http://gordonslibrarylinks.blogspot.com/2012_11_11_archive.html

Pahl, K., \& Rowsell, J. (2012). Literacy and education: Understanding the new literacy studies in the classroom (2nd ed.). London: Sage publications.

Selfe, C. L., \& Hawisher, G. E. (2004). Literate lives in the information age: Narratives of literacy from the United States. United States: Lawrence Erlbaum Associates.

Terms, P. I. (2013, September 13). Conceptions of curriculum and curriculum specialists: Philip. Retrieved April 6, 2016, from Conceptions of Curriculum, https://prezi.com/vxvmlyctrsof/ conceptions-of-curriculum-and-curriculum-specialists-philip/

\section{Citations, Quotes \& Annotations}

Hansen, D. t. (1999). Understanding Students. ProQuest.com, 14(2), 171-85. Retrieved from http://search. proquest.com/openview/e36f7c9d12d6bd48991b8c9762735e4f/1?pq-origsite=gscholar(Hansen, 1999)

Note: Reprint by Permission of ASCD (Association for Supervision and Curriculum Development, Alexandria, VA

Citation: Ibrahim Alfarhan, New Literacy in Saudi Arabia , American Research Journal of Humanities and Social Sciences, Volume 2, 2016; pp:1-6

Copyright (c) 2016 Ibrahim Alfarhan, This is an open access article distributed under the Creative Commons Attribution License, which permits unrestricted use, distribution, and reproduction in any medium, provided the original work is properly cited. 